\section{Kidney \\ Blood Pressure Research}

Kidney Blood Press Res 2013;37:190-198

\title{
Aliskiren, a Direct Renin Inhibitor, Improves Vascular Endothelial Function in Patients on Hemodialysis Independent of Antihypertensive Effect a Pilot Study
}

\author{
Hidekazu Moriya $^{\text {a }}$ Shuzo Kobayashi ${ }^{a}$ Takayasu Ohtake ${ }^{a}$ Daimu Tutumi ${ }^{a}$ \\ Yasuhiro Mochida ${ }^{a}$ Kunihiro Ishioka ${ }^{a}$ Machiko Oka ${ }^{a}$ Kyoko Maesato ${ }^{a}$ \\ Sumi Hidaka ${ }^{a}$ Shosaku Nomurab \\ a Department of Nephrology, Immunology, and Vascular Medicine, Shonan Kamakura General Hospital, \\ Kamakura, Kanagawa, Japan; b First Department of Internal Medicine, Kansai Medical University, \\ Moriguchi, Osaka, Japan
}

\section{Key Words}

Aliskiren • Flow-mediated dilatation - Platelet derived microparticle $\cdot$ Hemodialysis $\cdot$ Blood pressure

\begin{abstract}
Aims: Aliskiren inhibits the first step in the renin-angiotensin system (RAS) and recently has been shown to modulate vascular diseases via RAS-dependent and independent pathways. This study aimed to determine the effect of aliskiren-associated direct renin inhibition on endothelial function in patients on hemodialysis via flow-mediated dilatation (FMD) and platelet-derived microparticles (PDMP), as biomarkers of atherosclerosis. Methods: A 12-week prospective study was performed with 24 patients on hemodialysis who were administered $150 \mathrm{mg}$ orally aliskiren once daily for 12 weeks. Results: No significant difference were observed between pre-dialysis, home, and weekly averaged blood pressure at baseline and at 12 weeks $(151.5 \pm 8.5 / 80.9 \pm 12.9 \mathrm{mmHg}$ vs $150.3 \pm 15.3 / 78.9 \pm 21.2 \mathrm{mmHg}, 151.4 \pm 9.7 / 82.3$ $\pm 14.7 \mathrm{mmHg}$ vs $151.2 \pm 17.7 / 81.4 \pm 10.6 \mathrm{mmHg}$, and $156.0 \pm 18.3 / 81.9 \pm 9.4 \mathrm{mmHg}$ vs 152.5 $\pm 18.9 / 81.7 \pm 12.3 \mathrm{mmHg}$, respectively). FMD significantly increased from $2.54 \% \pm 1.45 \%$ at baseline to $3.11 \% \pm 1.37 \%$ at 12 weeks $(P=0.0267)$, and PDMP significantly decreased from $13.9 \pm 5.8 \mathrm{U} / \mathrm{mL}$ at baseline to $10.9 \pm 4.5 \mathrm{U} / \mathrm{mL}$ at 12 weeks $(P=0.0002)$. Conclusion: Aliskiren improved vascular endothelial function and platelet-endothelium activation in patients on hemodialysis independent of antihypertensive effect.
\end{abstract}




\section{Kidney \\ Blood Pressure Research}

Kidney Blood Press Res 2013;37:190-198

\begin{tabular}{l|l}
\hline DOI: $10.1159 / 000350144$ & (C) 2013 S. Karger AG, Basel
\end{tabular}

Publisned onine: IVIay 30, 2013

www.karger.com/kbr

\section{Introduction}

Cardiovascular diseases are the leading cause of mortality and morbidity in patients on hemodialysis. Hypertension and atherosclerosis play an important role in the development of cardiovascular diseases in such patients $[1,2]$. The renin-angiotensin-aldosterone system (RAAS) has a key role in the pathogenesis of hypertension in patients on hemodialysis.

Aliskiren, an orally active and direct renin inhibitor, was the first drug in its class to receive regulatory approval for the treatment of hypertension in 2007. Aliskiren inhibits the first rate-limiting step in the RAAS cascade that involves the conversion of angiotensinogen to angiotensin I and thereby reducing the synthesis of all subsequent components of the cascade [3]. In contrast, an angiotensin-converting enzyme (ACE) inhibitor or angiotensin receptor blocker (ARB) leads to a compensatory rise in the upstream components of the RAAS cascade, including plasma renin activity.

Renin induces various inflammatory reactions, including the activation of thrombogenic molecules [4] and intracellular signaling proteins independent of local angiotensin II [5], which are mediated via the recently characterized renin receptor [6]. Recently, aliskiren has been shown to modulate vascular diseases such as hypertension [7] and experimental atherosclerosis [8] via a RAAS-dependent or -independent pathway.

Endothelial dysfunction, observed via flow-mediated dilatation (FMD), of the brachial artery is observed during early-stage atherosclerosis and is thought to be a marker of vascular damage and/or a predictor of further cardiovascular events in subjects with cardiovascular disease risk factors [9-11]. However, microparticles released from platelets may play a role in the normal hemostatic response to vascular injury because of their prothrombinase activity. However, these particles also promote the adhesion of leukocytes to endothelial cells, leading to atherosclerosis [12]. Namba et al reported that patients with acute coronary syndrome and those with stable angina showed high titers of platelet-derived microparticles (PDMP; $33.8 \pm 56.9 \mathrm{U} / \mathrm{mL}$ and $10.8 \pm 8.0 \mathrm{U} / \mathrm{mL}$, respectively) compared with those in healthy individuals (5.9 U/mL) [13]. Therefore, PDMP is also a good marker of thrombotic and atherosclerotic disorders.

This study aimed to determine the effect of aliskiren-associated direct renin inhibition on endothelial function and platelet activation in patients on hemodialysis via FMD and PDMP.

\section{Patients and Methods}

\section{Patients}

All 178 patients on hemodialysis in our center were enrolled. Patients were considered hypertensive when systolic blood pressure (BP) before the hemodialysis session on the first hemodialysis day of the week was $>150 \mathrm{mmHg}$, even after accurate dry weight control and administration of antihypertensive drugs. Exclusion criteria were age $<40$ years or $>90$ years, a history of stroke, coronary arterial disease, chronic heart disease, and severe arrhythmia (atrial fibrillation, sustained ventricular tachycardia, sick sinus syndrome) and malignancy. All patients gave informed consent. The study was performed in accordance with the Declaration of Helsinki.

\section{Study protocol}

The study period was of 16 weeks with a 4-week observation period to fix dry weight and any drugs, including existing antihypertensives, and a 12-week treatment period involving treatment with a fixed dosage of aliskiren. All eligible patients entered the 12-week treatment period during which they were administered $150 \mathrm{mg}$ aliskiren orally once daily in the morning. The dosage of aliskiren was not changed during treatment, regardless of the BP values. In this treatment period, all of anti-hypertensive drugs which had been already prescribed were continued. BPs were measured before and at the end of hemodialysis sessions. Simultaneously, during the week, home BPs were measured after the patient woke in the morning and before bedtime. Weekly averaged blood pressure (WAB), the importance of which was 


\section{Kidney \\ Bloód Pressure Research}

Kidney Blood Press Res 2013;37:190-198

\begin{tabular}{l|l}
\hline DOI: $10.1159 / 000350144$ & (C) 2013 S. Karger AG, Basel
\end{tabular}

Published onlıne: IVlay 30, 2013

www.karger.com/kbr

highlighted in the Japanese Society for Dialysis Therapy guideline [14], was calculated from 20 points of BP measurements according to our previous reports $[15,16]$. The pre-dialysis BP was taken as the average of 3 BP measurements before starting the study and after 12 weeks of study protocol. Blood samples were obtained from arteriovenous shunts on a supine position after 15 minutes resting and before first dialysis sessions of the week. Plasma renin activity (PRA), plasma aldosterone concentration (PAC), high sensitive-C reactive protein (hs-CRP) levels, platelet-derived microparticles (PDMP), and other standard laboratory measurements were performed at baseline and after 12 weeks.

\section{Endothelium-dependent vasodilatation (via FMD)}

FMD of the brachial artery was assessed noninvasively using high-resolution ultrasound as described previously in detail [17-19]. For patients on hemodialysis, measurements were obtained before the first hemodialysis of the week. The subjects were instructed to abstain from smoking and from ingesting alcohol, caffeine, or antioxidant vitamins for at least $12 \mathrm{~h}$ prior to testing. The patients were asked to rest in the sitting position in a quiet, dark, air-conditioned room $\left(22-25^{\circ} \mathrm{C}\right)$ for $5 \mathrm{~min}$, after which their BPs were assessed using oscillometric methods (Omron Healthcare Co. Ltd., Kyoto, Japan). After the subjects had rested again for at least $15 \mathrm{~min}$ in a supine position in the same room, FMD was measured. Ultrasound was performed according to the guidelines for ultrasound assessment of the FMD of the brachial artery [11]. Using a 10$\mathrm{MHz}$ linear array transducer probe, the longitudinal image of the brachial artery on the arm opposite the arteriovenous shunt was recorded at baseline and then continuously for $5 \mathrm{~min}$, from $30 \mathrm{~s}$ before to at least $2 \mathrm{~min}$ after the cuff deflation that followed suprasystolic compression $(50 \mathrm{mmHg}$ above systolic blood pressure [SBP]). The diastolic diameter of the brachial artery was determined semi-automatically using an instrument equipped with software for monitoring the brachial artery diameter (Unex Co. Ltd., Nagoya, Japan). Briefly, a segment with clear anterior (media-adventitia) and posterior (intima-media) interfaces was manually determined. These border interfaces were then identified automatically on the A-mode waves. The diastolic per-beat diameter of the brachial artery was synchronized with the electrocardiographic R-wave and tracked automatically. FMD was estimated as the percent change in the diameter over the baseline value at maximal dilatation during reactive hyperemia. The FMD inter-session coefficient of variation was $9.5 \%$ in our laboratory.

\section{Measurement of PDMP}

An enzyme-linked immunosorbent assay (ELISA) kit for the detection of PDMPs [17-19] was obtained from JIMRO Co. Ltd. (Tokyo, Japan) as described previously in detail [20, 21]. Briefly, a blood sample was collected from an arteriovenous fistula into a vacutainer containing ethylenediaminetetraacetic acid-acid citrate dextrose solution (EDTA-ACD; Nipro Co. Ltd., Japan). The sample was gently mixed by inverting the tube once or twice and then left at room temperature for 2-3 h, followed by centrifugation at $8000 \mathrm{~g}$ for $5 \mathrm{~min}$ at room temperature. Immediately after centrifugation, we collected $200 \mu \mathrm{L}$ of the upper layer of supernatant from a 2-mL sample to avoid contamination and stored each sample at $-40^{\circ} \mathrm{C}$ until analysis. The results of the ELISA performed under the current experimental conditions are reproducible. The kit employed 2 monoclonal antibodies directed against platelet glycoproteins CD42b and CD42a (glycoprotein $\mathrm{Ib}$ and IX). One $\mathrm{U} / \mathrm{mL}$ of PDMP was defined as 24000 solubilized platelets $/ \mathrm{mL}$ in this ELISA.

\section{Statistical analyses}

This study was designed to have $80 \%$ power to detect a $5 \mathrm{mmHg}$ reduction in the blood pressure and $20 \%$ change in the titer of FMD and PDMP in the treatment of aliskiren, as compared with the baseline, assuming a two-sided alpha level of 0.05 . In power calculation, 25, 68, and 41 patients were needed in the comparison of blood pressure, FMD, and PDMP, respectively. All values were expressed as mean \pm standard deviation (SD) or median (range). The paired Student's $t$ test and Wilcoxon signed-rank test were used to compare values between baseline and at 12 weeks. All statistical analyses were performed with StatView 5.0 (SAS Institute, Cary, NC). $P$ values of $<0.05$ were considered to denote statistical significance. 


\section{Kidney \\ Blood Pressure Research}

Fig. 1. Patient flowchart.

Moriya/Kobayashi/Ohtake/Tutumi/Mochida/Ishioka/Oka/Maesato/Hidaka/Nomura:

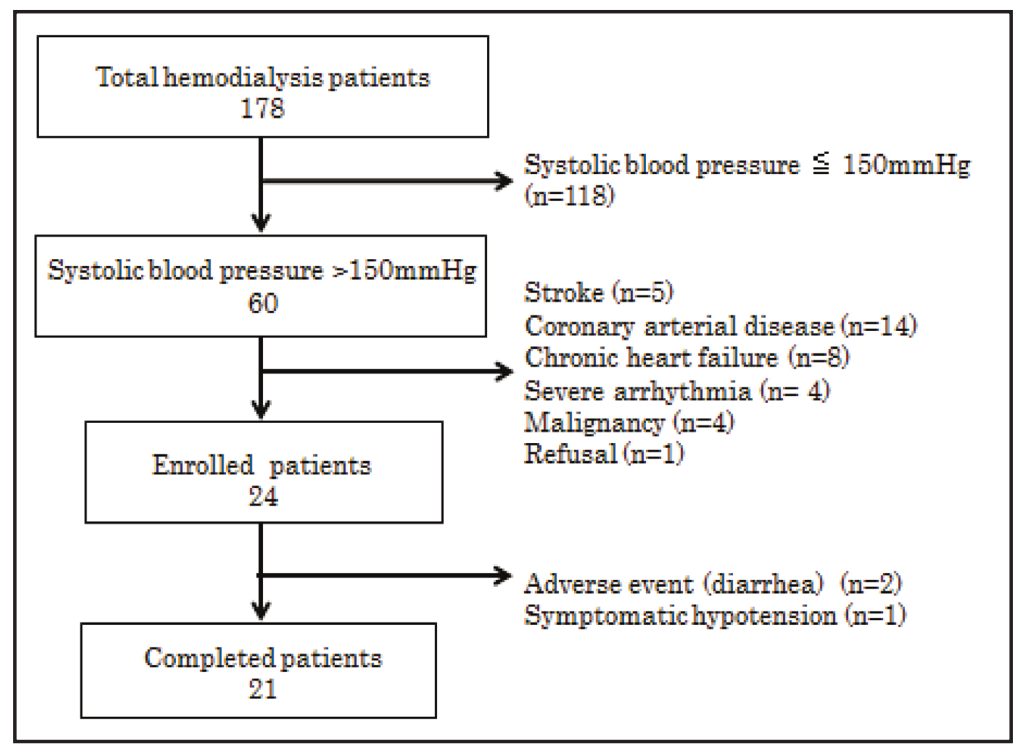

\section{Results}

A total of 24 patients were treated after the observation period. Of these 24,21 completed the study. Two patients discontinued treatment because of an adverse event (diarrhea), and 1 patient experienced symptomatic hypotension (Figure 1). Therefore, 3 patients were excluded from the analysis. Hyperkalemia was not observed in any patients.

Table 1 presents the clinical characteristics of the patients. The average age was $66.6 \pm$ 11.4 years, and the duration of dialysis therapy was 61.5 (7-324) months. Pre-dialysis systolic and diastolic BPs were $153.2 \pm 8.5 \mathrm{mmHg}$ and $82.8 \pm 10.3$, respectively. Of the 21 patients, 18 had been taking antihypertensive drugs before treatment, including ACE inhibitors (2 patients), ARBs (16 patients), calcium antagonists (13 patients), $\alpha$-blockers ( 4 patients), and $\alpha-\beta$ blockers ( 3 patients). Six patients had been taking 3 antihypertensive drugs.

\section{Effect of aliskiren on blood pressure}

No significant difference were observed between pre-dialysis systolic BPs at baseline and at 12 weeks $(151.5 \pm 8.5 \mathrm{mmHg}$ vs $150.3 \pm 15.3 \mathrm{mmHg}$, respectively; Figure $2 \mathrm{~A})$. With regard to home systolic BPs, no significant difference was observed between BPs at baseline and at 12 weeks $(151.4 \pm 9.7 \mathrm{mmHg}$ vs $151.2 \pm 17.7 \mathrm{mmHg}$, respectively; Figure $2 \mathrm{~B})$. WAB decreased slightly from $156.0 \pm 18.3 \mathrm{mmHg}$ at baseline to $152.5 \pm 18.9 \mathrm{mmHg}$ at 12 weeks. However, the change was not significant (Figure 2C).

No significant differences were observed between diastolic blood pressures at baseline and at 12 weeks (Figure $3 \mathrm{~A}-\mathrm{C})$; pre-dialysis $\mathrm{BP}(80.9 \pm 12.9 \mathrm{mmHg}$ vs $78.9 \pm 21.2 \mathrm{mmHg}$ ), home BP (82.3 $\pm 14.7 \mathrm{mmHg}$ vs $81.4 \pm 10.6 \mathrm{mmHg})$, and WAB $(81.9 \pm 9.4 \mathrm{mmHg}$ vs $81.7 \pm$ $12.3 \mathrm{mmHg}$ ).

\section{Effect of aliskiren on the RAAS system and hs-CRP level}

PRA decreased significantly from $2.36 \pm 3.23 \mathrm{ng} \cdot \mathrm{mL}^{-1} \cdot \mathrm{h}^{-1}$ at baseline to $1.22 \pm 1.67 \mathrm{ng} \cdot \mathrm{mL}^{-}$ ${ }^{1} \cdot \mathrm{h}^{-1}$ at 12 weeks $(P=0.0415)$. Contrary to the change of PRA, PAC increased significantly from $88.1 \pm 35.7 \mathrm{pg} / \mathrm{mL}$ at baseline to $109.4 \pm 28.6 \mathrm{pg} / \mathrm{mL}$ at 12 weeks $(P=0.0019)$. hs-CRP levels did not show any significant change.

Changes of FMD and PDMP

FMD significantly increased from $2.54 \% \pm 1.45 \%$ at baseline to $3.11 \% \pm 1.37 \%$ at 12 weeks $(P=0.0267$; Figure 4). PDMP significantly decreased from $13.9 \pm 5.8 \mathrm{U} / \mathrm{mL}$ at baseline 


\section{Kidney Blood Pressure Research}

Table 1. Patients baseline characteristics $(n=21)$
Kidney Blood Press Res 2013;37:190-198

\begin{tabular}{l|l}
\hline DOI: 10.1159/000350144 & $\begin{array}{l}\text { C } 2013 \text { S. Karger AG, Basel } \\
\text { www.karger.com/kbr }\end{array}$ \\
\hline Published onlIne: IVIay 30, 2013 &
\end{tabular}

Moriya/Kobayashi/Ohtake/Tutumi/Mochida/Ishioka/Oka/Maesato/Hidaka/Nomura: Aliskiren and Vascular Endothelial Function

\begin{tabular}{lc}
\hline Age (years) & $66.6 \pm 11.4$ \\
Gender (M/F) & $13 / 8$ \\
Body mass index & $20.5 \pm 3.4$ \\
Hemodialysis duration (months) & $61.5(7-324)$ \\
Initial nephropathy & \\
$\quad$ diabetes mellitus & 7 \\
$\quad$ chronic glomerulonephritis & 6 \\
polycystic kidney disease & 4 \\
hypertensive nephrosclerosis & 3 \\
lupus nephritis & 1 \\
ANCA vasculitis & 1 \\
Medication & \\
Calcium antagonist & 12 \\
Angiotensin converting enzyme inhibitor & 2 \\
angiotensin receptor blocker & 14 \\
ab-blocker & 3 \\
a-blocker & 4 \\
systolic blood pressure (mmHg) & $153.2 \pm 8.5$ \\
Diastolic blood pressure (mmHg) & $82.8 \pm 10.3$ \\
Heart rate (/min) & $69.3 \pm 9.3$ \\
high sensitive-CRP (mg/dl) & $0.146 \pm 0.191$ \\
Plasma renin activity (ng/ml/hr) & $0.059(0.003-0.676)$ \\
Plasma aldosterone concentration (pg/ml) & $2.36 \pm 3.23$ \\
Hemoglobin (g/dl) & $1.25(0.2-9.9)$ \\
Total protein (g/dl) & $88.11 \pm 35.72$ \\
\hline & $65.5(35.4-182.4)$ \\
& \\
& \\
& \\
& \\
&
\end{tabular}

Fig. 2. Changes in (A) pre-dialysis systolic blood pressure, (B) home systolic blood pressure, (C) systolic weekly averaged blood pressure (WAB) from baseline to week 12. No significant differences observed in all components of blood pressure between baseline and week 12 .

\section{B}
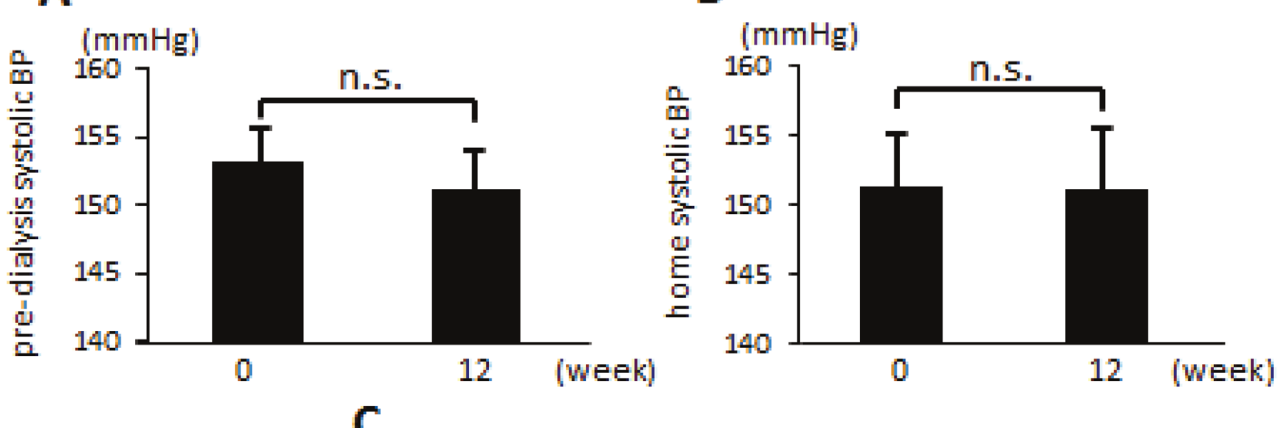

C

n.s.

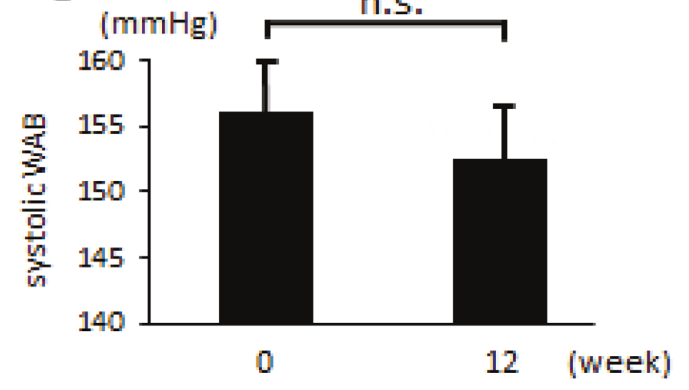

to $10.9 \pm 4.5 \mathrm{U} / \mathrm{mL}$ at 12 weeks ( $P=0.0002$; Figure 5). Of 21 patients, 19 showed a decrease in PDMP. However, the change in FMD did not significantly correlate with the change in PDMP. 


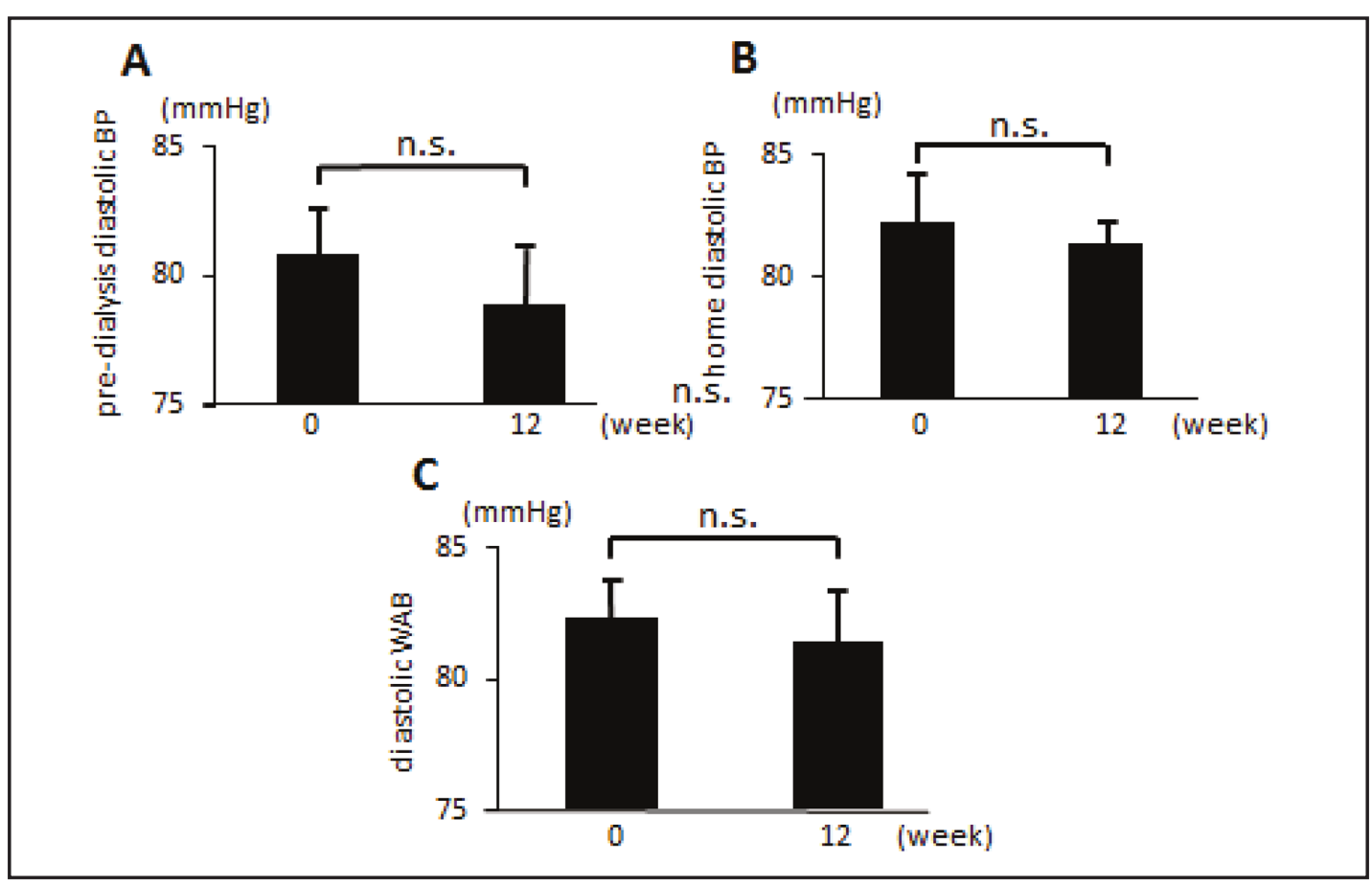

Fig. 3. Changes in (A) pre-dialysis diastolic blood pressure, (B) home diastolic blood pressure, (C) diastolic weekly averaged blood pressure (WAB) from baseline to week 12. No significant difference observed in all components of blood pressure between baseline and week 12 .

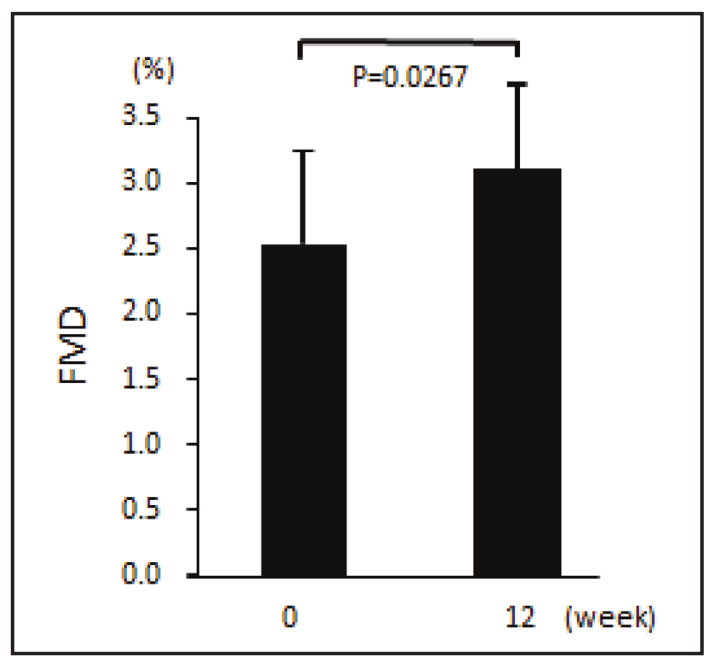

Fig. 4. Changes in flow-mediated dilatation (FMD) from baseline to week 12. FMD increased significantly from baseline to week $12(P=0.0267)$.

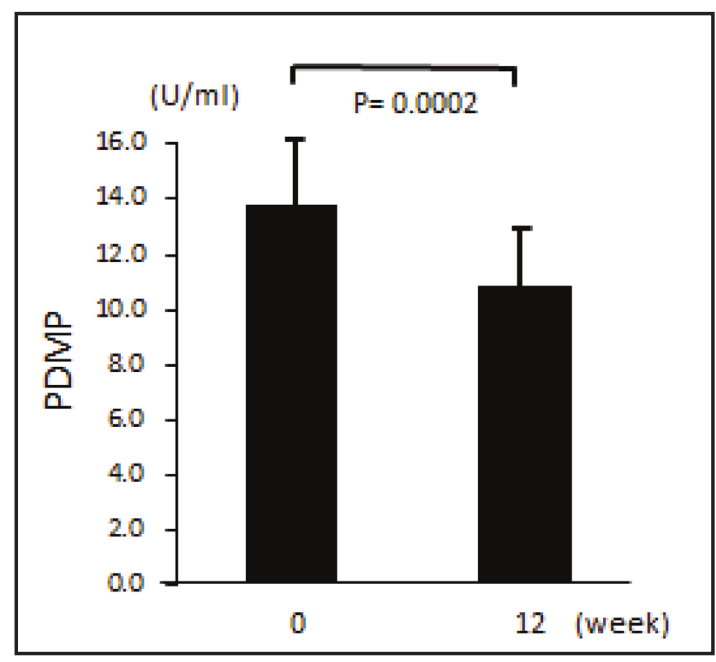

Fig. 5. Changes in platelet-derived microparticles (PDMP) from baseline to week 12. PDMP decreased significantly from baseline to week $12(P=0.0002)$.

\section{Discussion}

The major finding of our present study was that aliskiren, a direct renin inhibitor, improved FMD and PDMP, regardless of the effect of lowering BP. Previously, aliskiren had been shown to modulate vascular diseases such as hypertension [7] and experimental atherosclerosis $[8,22]$ via RAS-dependent and independent pathways. However, the effect of 


\section{Kidney Blood Pressure Research}

Kidney Blood Press Res 2013;37:190-198

\begin{tabular}{l|l}
\hline DOI: 10.1159/000350144 & (C) 2013 S. Karger AG, Basel
\end{tabular}

Published onine: IVIay 30, 2013

www.karger.com/kbr

oriya/Kobayashi/Ohtake/Tutumi/Mochida/Ishioka/Oka/Maesato/Hidaka/Nomura: Aliskiren and Vascular Endothelial Function

renin inhibitors on endothelial function in humans is not yet clear. Therefore, we focused on the effects of direct renin inhibition by aliskiren on FMD and leukocyte-endothelial interaction in humans, especially patients on hemodialysis who were prone to atherosclerotic diseases.

Lu et al. [8] reported that aliskiren dramatically reduced the atherosclerotic lesion size in a dose-dependent fashion in the experiments that were conducted over 12 weeks. The study suggested that macrophages without renin or with renin inhibitor protected against plaque development and expansion. Ino also reported that aliskiren-associated renin inhibition profoundly reduced leukocyte recruitment in perivascular cuff injury-induced acute vascular inflammation in mice, independent of BP [23]. A significant component of the cardiovascular protection appeared to be independent of BP lowering, suggesting important and direct roles for the RAAS within the arterial wall itself.

PDMPs play an important role in the clotting process. Therefore, an increase in PDMPs is may cause hypercoagulability. In addition, PDMPs promote the expression of adhesion molecules via monocytes and endothelial cells, and these microparticles may participate in the development or progression of atherosclerosis [12]. High shear stress can initiate both platelet aggregation and shedding of procoagulant-containing PDMP, suggesting that PDMP generation by high shear stress occurs in small diseased arteries and arterioles.

The average titer of PDMP in patients on hemodialysis in this study was $13.9 \pm 5.8 \mathrm{U} / \mathrm{mL}$ at baseline, which was higher than that of patients with angina $(10.8 \pm 8.0 \mathrm{U} / \mathrm{mL})$, according to the study by Namba [13]. In other words, patients on hemodialysis have a higher risk of thromboembolic and atherosclerotic events than patients with angina. Namba revealed that a high PDMP level was an independent predictor for secondary thrombotic events. From these data, aliskiren has a potential to reduce atherosclerotic events in patients on hemodialysis by inhibiting platelet aggregation.

With respect to the mechanism of renin inhibitor on endothelial function, Imanishi reported that aliskiren improved impaired oxide bioavailability and protected against atherosclerotic changes [24]. In addition, Morishita reported the effects of aliskiren on BP and the predictive biomarkers for cardiovascular disease by improving oxidative stress in hemodialysis patients [25]. These results suggest that aliskiren improves endothelial function by regulating oxidative stress and inhibiting leukocyte-endothelial interaction, thereby protecting against atherosclerosis.

ACE inhibitors and ARBs also have an effect on endothelial function. However, the present study showed that aliskiren had an additional effect in patients who were previously being administered these drugs. In this respect, several studies have shown an association of elevated PRA with an increased risk of cardiovascular events, and some reports have pointed out a potential role for renin receptor in RAAS-independent signaling by renin $[4,6,26]$.

In our study, BP did not change significantly with the $150 \mathrm{mg}$ of aliskiren that had been reported to be effective in other study [25]. This study showed that 16 out of 25 patients had medication of ACE inhibitor or ARB, and 150mg of aliskiren decreased blood pressure significantly. However, baseline blood pressure of this study was $169.0 \pm 20.1 \mathrm{mmHg}$ and higher than that of our study. In our study, the dosage of aliskiren was fixed without any target of blood pressure. It might not be sufficient to control blood pressure in patients on hemodialysis who already had resistance to several types of antihypertensive drugs. $300 \mathrm{mg}$ of aliskiren might decrease blood pressure significantly. Aliskiren showed improvement of FMD and PDMP regardless of the effect of lowering BP. For this reason, partial RAAS blockade may be sufficient to control endothelial function and adhesion molecules, and regulation of renin is more important to control endothelial function rather than other components of the RAAS cascade.

This study has some limitations. First, a placebo control or cross-over design is lacking and the number of patients recruited in this study was small. The subjects were under various medications, including RAS blockade. Selection bias and medication might have affected the results. Second, several studies demonstrated that aliskiren decreased both the level of plasma renin activity and plasma aldosterone concentration in patients without renal dysfunction. However, the present study showed that patients on hemodialysis had increased 


\section{Kidney \\ Blood Pressure Research}

aldosterone levels. Potassium level might affect the level of PAC, although potassium levels did not show any significant change between baseline and 12 weeks. Third, in this study, endothelial dependent vasodilation was estimated. However, it is unknown that aliskiren has an effect to endothelial-independent vasodilation.

\section{Conclusion}

Aliskiren improved vascular endothelial function and platelet-endothelium interactions in patients on hemodialysis independent of antihypertensive effect.

\section{Conflict of Interests}

The authors declare no conflict of interest.

\section{References}

1 Charra B, Calemard M, Laurent G: Importance of treatment time and blood pressure control in achieving long-term survival on dialysis. Am J Nephrol 1996;16:35-44.

- Tomita J, Kimura G, Inoue T, Inenaga T, Sanai T, Kawano Y, Nakamura S, Baba S, Matsuoka H, Omae T: Role of systolic blood pressure in determining prognosis of hemodialyzed patients. Am J Kidney Dis 1995;25:405412.

3 Staessen JA, Li Y, Richart T: Oral renin inhibitors. Lancet 2006;368:1449-1456.

4 Nguyen G, Delarue F, Berrou J, Rondeau E, Sraer JD: Specific receptor binding of rein on human mesangial cells in culture increases plasminogen activator inhibitor-1. Kidney Int 1996;50:1897-1903.

-5 Feldt S, Batenburg WW, Mazak I, Maschke U, Wellner M, Kvakan H, Dechend R, Fiebeler A, Burckle C, Contrepas A, Jan Danser AH, Bader M, Nquyen G, Luft FC, Muller DN: Prorenin and renin-induced extracellular signal-regulated kinase $1 / 2$ activation in monocytes is not blocked by aliskiren or the handleregion peptide. Hypertension 2008;51:682-688.

6 Nguyen G, Delarue F, Burckle C, Bouzhir L, Giller T, Sraer JD: Pivotal role of the renin/prorenin receptor in angiotensin II production and cellular responses to renin. J Clin Invest 2002;109:1417-1427.

-7 Gradman AH, Schmieder RE, Lins RL Nussberger J, Chiang Y, Bedigian MP: Aliskiren, a novel orally effective renin inhibitor, provides dose-dependent antihypertensive efficacy and placebo-like tolerability in hypertensive patients. Circulation 2005;111:1012-1018.

-8 Lu H, Rateri DL, Feldman DL, Jr RJ, Fukamizu A, Ishida J, Oesterling EG, Cassis LA, Daugherty A: Renin inhibition reduces hypercholesterolemia-induced atherosclerosis in mice. J Clin Invest 2008;118:984-993.

-9 Windlansky ME, Gokce N, Keaney JF Jr, Vita JA: The clinical implications of endothelial dysfunction. J Am Coll Cardiol 2003;42:1149-1160.

10 Moens AL, Goovaerts I, Claeys MJ, Vrints CJ: Flow-mediated vasodilation: a diagnostic instrument, or an experimental tool? Chest 2005;127:2254-2263.

-11 Corretti MC, Anderson TJ, Benjamin EJ, Celermajer D, Charbonneau F, Creager MA, Deanfield J, Drexler H, Gerhard-Herman M, Herrington D, Vallance P, Vita J, Voger R; International Brachial Artery Reactivity Task Force: Guideline for the ultrasound assessment of endothelial-dependent flow-mediated vasodilation of the brachial artery: a report of the International Brachial Artery Reactivity Task Force. J Am Coll Cardiol 2002;39:257-265.

12 Nomura S, Tandon NN, Nakamura T, Cone J, Fukuhara S, Kambayashi J: High-shear-stress- induced activation of platelets and microparticles enhances expression of cell adhesion molecules in THP-1 and endothelial cells. Atherosclerosis 2001;158:277-287. 


\section{Kidney \\ Blood Pressure Research}

Kidney Blood Press Res 2013;37:190-198

DOI: $10.1159 / 000350144$

Publisned ontrne: IVlay 30, 2013

(C) 2013 S. Karger AG, Basel

www.karger.com/kbr

13 Namba M, Tanaka A, Shimada K, Ozeki Y, Uehata S, Sakamoto T, Nishida Y, Nomura S, Yoshikawa J: Circulating platelet-derived microparticles are associated with atherothrombotic events: a marker for vulnerable blood. Arterioscler Thromb Vasc Biol 2007;27:255-256.

14 Hirakata H, Nitta K, Inaba M, Shoji T, Fujii H, Kobayashi S, Tabei K, Joki N, Hase H, Nishimura M, Ozaki S, Ikari Y, Kumada Y, Tsuruya K, Fujimoto S, Inoue T, Yokoi H, Hirata S, Shimamoto K, Kugiyama K, Akiba T, Iseki K, Tsubakihara Y, Tomo T, Akizawa T: Japanese Society for Dialysis Therapy Guidelines for Management of Cardiovascular Diseases in Patients on Chronic Hemodialysis. Ther Apher Dial 2012;16:387-435.

-15 Moriya H, Ohtake T and Kobayashi S: Aortic stiffness, left ventricular hypertrophy and weekly averaged blood pressure (WAB) in patients on haemodialysis. Nephrol Dial Transplant 2007;22:1198-1204.

16 Moriya H, Oka M, Maesato K, Mano T, Ikee R, Ohtake T, Kobayashi S: Weekly averaged blood pressure is more important than a single-point blood pressure measurement in the risk stratification of dialysis patients. Clin J Am Soc Nephrol 2008;3:416-422.

17 Inoue T, Matsuoka H, Higashi Y, Ueda S, Sata M, Shimada KE, Ishibashi Y, Node K; Vascular Failure Workshop Group: Flow-mediated vasodilation as a diagnostic modality for vascular failure. Hypertens Res 2008;31:2105-2113.

- 18 Tomiyama H, Matsumoto C, Yamada J, Teramoto T, Abe K, Ohta H, Kiso Y, Kawauchi T, Yamashina A: The relationships of cardiovascular disease risk factors to flow-mediated dilatation in Japanese subjects free of cardiovascular disease. Hypertens Res 2008;31:2019-2025.

-19 Verbeke FH, Pannier B, Guerin AP, Boutouyrie P, Laurent S, London GM: Flow-mediated vasodilation in endstage renal disease. Clin J Am Soc Nephrol 2011;6:2009-2015.

20 Nomura S, Ozaki Y, Ikeda Y: Function and role of microparticles in various clinical settings. Thromb Res 2008;123:8-23.

21 Nomura S, Shouzu A, Taomoto K, Togane Y, Goto S, Ozaki Y, Uchiyama S, Ikeda Y: Assessment of an ELISA kit for platelet-derived microparticles by joint research at many institutes in Japan. J Atheroscler Thromb 2009;16:878-887.

22 Nussberger J, Aubert JF, Bouzourene K, Pellegrin M, Hayoz D, Mazzolai L: Renin inhibition by aliskiren prevents atherosclerosis progression: comparison with irbesartan, atenolol, and amlodipine. Hypertension 2008;51:1306-1311.

23 Ino J, Kojima C, Osaka M, Nitta K, Yoshida M: Dynamic observation of mechanically-injured mouse femoral artery reveals an anti-inflammatory effect of renin inhibitor. Arterioscler Thromb Vasc Biol 2009;29:18581863.

24 Imanishi T, Tsujioka H, Ikejima H, Kuroi A, Takarada S, Kitabata H, Tanimoto T, Muragaki Y, Mochizuki S, Goto M, Yoshida K, Akasaka T: Renin inhibitor aliskiren improves impaired nitric oxide bioavailability and protects against atherosclerotic changes. Hypertension 2008;52:563-572.

25 Morishita Y, Hanawa S, Chinda J, Iimura O, Tsunematsu S, Kusano E: Effects of aliskiren on blood pressure and the predictive biomarkers for cardiovascular disease in hemodialysis-dependent chronic kidney disease patients with hypertension. Hypertens Res 2011;34:308-313.

-26 Saris JJ, 'tHoen PA, Garrelds IM, Dekkers DH, den Dunnen JT, Lamers JM, Jan Danser AH: Prorenin induces intracellular signaling in cardiomyocytes independently of angiotensin II. Hypertension 2006;48:564-571. 